\title{
DEL SOL NACIENTE (1983-1984), DE GRISELDA GAMBARO: GUERRA DE MALVINAS, DICTADURA Y PATRIARCADO
}

\author{
GRISELDA GAMBARO'S DEL SOL NACIENTE (1983-1984): \\ MALVINAS WAR, DICTATORSHIP AND PATRIARCHY
}

\author{
Ricardo DUBATTI \\ CONICET / Universidad de Buenos Aires, \\ Instituto de Artes del Espectáculo \\ ricardo.dubatti@gmail.com
}

Resumen: En nuestra investigación relevamos aquellos textos dramáticos argentinos que se refieren a la Guerra de Malvinas (1982), acontecimiento que constituye una presencia sensible en la sociedad argentina contemporánea (Lorenz, 2012). Estudiamos las representaciones (Chartier, 1992) por las que el teatro opera como constructo memorialista (Vezzetti, 2002) que activa los trabajos de la memoria (Jelin, 2002) y habla de lo "no decible" (Mancuso, 2010). Analizamos en Del sol naciente (1983/1984), de Griselda Gambaro, cómo la poética configura una lectura de la guerra desde una crítica antipatriarcal y antidictatorial desde una concepción de la memoria como gran compartir.

Palabras clave: Del sol naciente. Griselda Gambaro. Poética Comparada. Metáfora. Representación.

Abstract: In the frame of our research we examine those Argentine dramatic texts about the Malvinas War (1982), an event which constitutes a sensitive presence in contemporary Argentine society (Lorenz, 2012). We study the representations (Chartier, 1992) through which drama operates as a memorialist construct (Vezzetti, 2002) that triggers the workings of memory (Jelin, 2002) and speaks of the "unspeakable" (Mancuso, 2010). In Del sol naciente (1983/1984), a dramatic text by Griselda Gambaro, 
we analyze how its poetics yields a reading of the above-mentioned war from an anti-patriarchal and anti-dictatorial criticism and a conception of memory as great sharing.

Key Words: Del sol naciente. Griselda Gambaro. Comparative Poetics. Metaphor. Representation.

En el marco de una investigación mayor que estamos desarrollando ${ }^{1,}$ analizaremos la poética del texto dramático Del sol naciente, de Griselda Gambaro $^{2}$, en relación con la representación de la Guerra de Malvinas en el teatro argentino.

La Guerra de Malvinas fue el último acontecimiento bélico internacional de la Argentina, impulsado contra el Reino Unido por el gobierno de facto de la dictadura cívico-militar, ya en su etapa de declive. Se extendió entre el 2 de abril y el 14 de junio de 1982. Su causa principal - aunque no la única - consistió en la disputa por la soberanía de las Islas Malvinas, Sandwich y Georgias del Sur. Tras un total de 74 días, concluyó con la rendición argentina, que sufrió 649 bajas. La guerra marcó un punto de quiebre (Escudero, 1997: 26) y aceleró la salida del autodenominado "Proceso de Reorganización Nacional" (1976-1983) (Ministerio de Educación Presidencia de la Nación, 2009). Arraigada sobre un imaginario simbólico nacionalista (Guber, 2001; Lorenz, 2012) fuertemente sedimentado (Mancuso, 2011), porta un peculiar carácter dilemático (Rozitchner, 2015) y constituye en la postdictadura, hasta hoy, una zona sensible para la sociedad argentina. La posguerra sigue aconteciendo como trauma social por sus consecuencias y se reaviva permanentemente en tanto la disputa no ha concluido ${ }^{3}$.

\footnotetext{
'Beca Doctoral del CONICET: "Representaciones de la Guerra de Malvinas (1982) y sus consecuencias socioculturales en el teatro argentino (1982-2017): poéticas dramáticas, historia y memoria”. Bajo la dirección de Hugo Mancuso y la codirección de Mauricio Tossi.

${ }^{2}$ Griselda Gambaro (Buenos Aires, 1928) es dramaturga, novelista, cuentista y ensayista. Inicia su producción en los años sesenta y, desde entonces hasta el presente, es referente insoslayable de la cultura argentina e hispanoamericana. Perseguida durante la dictadura cívico-militar, se exilió en Barcelona desde 1977 hasta 1980, cuando retornó a la Argentina.

${ }^{3}$ Postdictadura y posguerra portan una relación doble, de cierre y continuidad, con los hechos del pasado reciente. Como sugiere el prefijo post-, pueden interpretarse como "lo que viene después de" y como "lo que ocurre como resultado de" la dictadura y la guerra, respectivamente. Esta doble
} 
Escrito en 1983 (un año después de finalizada la guerra) y estrenado en septiembre de 1984 en el Teatro Lorange de Buenos Aires, con dirección general de Laura Yusem ${ }^{4}$ (a poco más de dos años de la rendición y a apenas diez meses de la restitución de la democracia ${ }^{5}$ ), Del sol naciente forma parte de un corpus de más de ochenta textos teatrales argentinos (R. Dubatti, 2019) que trabajan con las representaciones (Chartier, 1992) de la guerra. Como medio imaginístico específico (Rozik, 2014) y por su relación con el acontecimiento convivencial (J. Dubatti, 2012b), las poéticas del teatro - texto dramático y/o espectacular - presentan condiciones singulares para las representaciones, diferenciables de las que realizan la literatura, el cine, la historieta o la plástica. El teatro no es meramente otro formato para las representaciones, sino que exige semantizar la forma teatral (Szondi, 1994). Las poéticas teatrales se articulan como metáforas epistemológicas (Eco, 1984), que permiten simultáneamente volver sobre el pasado y aportar nuevas miradas desde el presente. Estas condiciones hacen posible pensar el teatro como dispositivo artístico complejo ("constructo memorialista", Vezzetti, 2002: 14) de rasgos específicos para la activación de "los trabajos de la memoria" (Jelin, 2002: 12) en la postdictadura y la posguerra. La cantidad de textos teatrales que constituyen el mencionado corpus demuestra la relevancia y continuidad del teatro en el desarrollo de esta función memorialista.

Para nuestro análisis seguiremos cuatro instancias: presentaremos una selección de las declaraciones de la dramaturga y de la bibliografía académica que han explicitado las relaciones entre Del sol naciente y la Guerra de Malvinas; luego describiremos cómo la representación de la

condición se hace manifiesta a través de procesos que continúan vivos, en el mismo sentido en que Agamben (2000) reflexiona sobre Auschwitz. La noción de postdictadura (Cattaruzza, 2012: 71-91; J. Dubatti, 2012a) incluye a la de posguerra, y la vincula con procesos sociales, históricos y políticos más amplios, dentro de los cuales se insertan las consecuencias de la guerra (entre otros, Vezzetti, 2002: 58, 93).

${ }^{4}$ Ficha artístico-técnica: Elenco: Soledad Silveyra (Suki), Lidia Catalano (Ama), Ulises Dumont (Obán), Pablo Brichta (Tísico), Mario Alarcón (Oscar). Escenografía y vestuario: Graciela Galán. Música: Pablo Ortiz. Asistencia de dirección: Tito Otero. Puesta en escena: Laura Yusem y Bettina Muraña. Dirección general: Laura Yusem. El espectáculo incluye haikus traducidos por Osvaldo Svanascini y publicados en Tres maestros del haiku (1976).

${ }^{5}$ La restitución democrática se produce el 10 de diciembre de 1983. El último año del gobierno de facto marcó una tensa transición hacia la democratización por la convocatoria de los partidos a las elecciones. Para un panorama más amplio sobre el clima político, social y cultural del momento, remitimos a 1983. El año de la democracia, de Germán Ferrari (2013). 
guerra es un componente fundamental de la poética en tanto articula la acción y la estructura del texto dramático; en tercer lugar, examinaremos la relación entre los acontecimientos representados y los topics (Eco, 1993: 125-134) con los que en el texto se configura un campo referencial vinculado al hecho histórico a través de la formulación de una poética de la anamorfosis; finalmente, analizaremos la propuesta semántica y la lectura crítica que realiza Gambaro en su texto dramático sobre la Guerra de Malvinas.

\section{EL JAPÓN FEUDAL COMO METÁFORA DE LA ARGENTINA DICTATORIAL}

La historia de Del sol naciente transcurre en el Japón feudal. Se trata de un Japón feudal sui generis, una construcción poética que no reivindica ninguna precisión arqueológica o de ilustración documental. El texto dramático no incluye ninguna referencia explícita ni a la dictadura argentina, ni a la Guerra de Malvinas. De hecho, hay investigadores que analizan la pieza sin establecer relación con la Guerra de Malvinas (entre otros, Lusnich, 2001b; Contreras, 1994a y 1994b, quien se centra en las tensiones entre violencia patriarcal y resistencia femenina). ¿Querría hablarnos Gambaro de Japón, o se estará valiendo de esa materia como metáfora que reenvía a otros referentes, por ejemplo, su propio contexto, la Argentina contemporánea? Podemos considerar el Japón feudal gambariano, sus reglas patriarcales y sus prácticas bélicas, como una metáfora del régimen social en la Argentina de la dictadura y la posdictadura.

Es frecuente en el teatro argentino apelar a la mediación metafórica en la representación del referente por varias razones: a) para evitar la censura o cualquier tipo de ataque en tiempos históricos de ausencia de estado de derecho, o de inminencia de peligrosidad y violencia (como explica Eduardo Pavlovsky en relación a la dictadura de la "Revolución Argentina", 1976: 36); b) para diferenciar el arte (práctica simbólica connotativa) de otras prácticas de la comunicación (denotativas), como el periodismo y la historia, en una suerte de división del trabajo; c) para otorgar a lo representado las potencias de la "verdad metafórica" (Oliveras, 2007: 183-200) o "verdad de la ficción" (Presas, 1997) y la semiosis ilimitada de la imaginación y la poiesis, y exceder así la verdad 
verificable del documentalismo histórico o el registro social. La metáfora ficcional, al mismo tiempo que garantiza la conexión con el referente histórico, multiplica la producción de sentido por la vía del arte (Rozik, 2008). Creemos que Gambaro elige como metáfora el Japón feudal porque se trata de un contexto muy distante (tanto en el espacio y el tiempo como en cuanto a la cultura), y esa distancia crea un guiño de complicidad con el espectador: la pieza no quiere hablar de Japón, se vale del Japón para hablar de otra cosa.

La primera en explicitar el vínculo referencial entre el Japón medieval, la dictadura argentina y la Guerra de Malvinas fue la autora. En el semanario El Periodista, número correspondiente del 6 al 12 de octubre de 1984, Gambaro señala:

Escribi este texto el año pasado [1983] y lo hice con cierta rapidez, como me sucede cuando tengo el tema y una idea general de la estructura. Aparece a raiz de un sueño, tal como me pasó con El campo [de 1967]. En este caso soñé que había escrito una pieza de ambiente japonés, que era perfecta. Al despertar lamenté que no pudiera reproducir esa perfección. En esos dias se recordaba un nuevo aniversario de las Malvinas, que es en mí un peso recurrente. $Y$ de pronto se asociaron las dos cosas. Pensé que el ambiente japonés me permitiría una gran libertad imaginativa y el uso de un lenguaje particular, que no fuera tomado directamente de nuestra forma de hablar cotidiana. A mi me importa mucho la palabra y presto atención a la escritura de las piezas, porque otorgo a la palabra un valor dramático de primer orden. Me sedujo también la libertad que me suministraria el distanciamiento y las situaciones que podría crear a través de cómo yo veía Japón. De ninguna manera pensé en una reconstrucción de época ni siquiera aproximada. Simplemente es mi propio recuerdo de ese Japón a través de alguna película que vi, un libro que leí o, tal vez, de algunas de las estampas de Okusai [sic] $]^{6}$ (Catena, 1984: 34).

Son abundantes las referencias en la investigación académica. Stella Maris Martini analiza un parlamento de la pieza y concluye que

6 Referencia al pintor japonés Katsushika Hokusai (1760-1849). 
se expresa "en clara alusión al doloroso temas de los combatientes de las Malvinas" (1989: 106). Jean Graham-Jones hace una breve mención en su comentario sobre Del sol naciente: "Set in a medieval Japan of shoguns and courtesans but just as easily read as a recent Argentina of the Malvinas/Falklands War [...]" (2000: 132; énfasis nuestro) ${ }^{\mathrm{E}} \mathrm{n}$ su libro Las islas imaginadas. La guerra de Malvinas en la literatura y el cine argentinos, Julieta Vitullo incluye el texto de Gambaro en su "apéndice de ficciones" (2012: 193-194). La introducción del apéndice remarca: "Con pretensiones de exhaustividad [sic], esta lista reúne cuarenta ítems, entre cuentos, novelas, obras teatrales y películas, que se centran en la guerra de Malvinas o la tocan de manera más o menos lateral" (193). En el manual Malvinas en el aula. Una propuesta desde la literatura se selecciona un fragmento de la pieza y los autores sugieren que "la situación de los jóvenes guerreros del conflicto japonés recuerda a la de los conscriptos de Malvinas" (Ciccone, Heredia, Irazábal y Suñer, 2017: 55). En contraste, Mónica Botta afirma en un artículo sobre Bar Ada (1993), pieza teatral de Jorge Leyes, que "el tema de la guerra [de Malvinas] ya aparece en la literatura dramática anterior, pero siempre a través de un tratamiento oblicuo del referente como es el caso de la pieza de Griselda Gambaro, Del sol naciente (1984) y La soga (1991), de Beatriz Mosquera" (2006: s/p). Por su parte, Susana Tarantuviez (2007: 279-281) y María Florencia Heredia (2013: 48) consideran que el texto alude de manera concreta a la Guerra de Malvinas.

No solo se trata de menciones. En "Más cerca del cañón que del canon: las primeras ficciones de la guerra de Malvinas" (2016: 178-191), Victoria Torres analiza detenidamente tres casos de distintas disciplinas, entre los que se incluye la pieza de Gambaro. Observa sobre Del sol naciente que sus personajes "han quedado desamparados después de terminado un enfrentamiento bélico que se parece mucho al de Malvinas, y del que Obán participa en tanto jefe militar" (189). Luego agrega: "Los jóvenes combatientes en el conflicto japonés corren una suerte parecida a los conscriptos de las islas del Atlántico Sur: no sólo quedan desamparados a su regreso, sino que además se los quiere enterrar para olvidarlos, cosa a la que ellos se resisten deambulando por las calles" (189). Finalmente, al referirse a los tres casos que estudia, concluye que "comparten, actualizan y activan nuestra memoria presente cumpliendo con esa premisa sobre la que la ficción urgente de aquella primera postguerra [sic] parece haber 
insistido tenazmente: que la memoria tiene razón de ser solo si puede mantenerse viva" (190-191).

En cuanto a la poética dramática de Del sol naciente, Ana Laura Lusnich la analiza en el proceso de una "intensificación" del "realismo crítico" (2001b: 346). Para esta autora, durante la década de 1970 el "absurdismo" de las primeras obras de Gambaro absorbe gradualmente procedimientos realistas, con Real envido (1980) y La malasangre (1981) como textos ya plenamente configurados desde el realismo crítico (2001a: 147) ${ }^{7}$ ${ }^{\mathrm{T}}$ arantuviez (2007) concuerda con esta lectura y, al proponer una periodización de la producción de Gambaro, incluye la pieza como parte de un corpus de textos dramáticos atravesados por un "momento de idealización" donde "el personaje femenino es quien encarna la axiología positiva en la que se destacan los valores de la solidaridad, la compasión, y la lucha por la libertad: representación de lo femenino como 'la heroína"' (139; énfasis en el original).

Sin embargo, Del sol naciente trabaja su poética con procedimientos que se apartan del realismo crítico para producir un efecto de extrañamiento. Destaquemos los principales: la figura del que regresa reiteradamente de la muerte (Oscar), como veremos, en variante involuntaria, y que reaparece a pesar de que vuelve a ser asesinado, incluso enterrado, por Obán; la posible atribución de la condición de muertos a los soldados del ejército que regresa vencido y erra por las calles; el carácter metafórico distanciador del cronotopo Japón feudal, que disloca la ilusión de contigüidad - característica del realismo - entre lo representado y la serie social contemporánea. Por el contraste problematizado entre el mundo representado y el régimen de experiencia social de los lectores/espectadores (Barrenechea, 1978), los muertos vivos, la trama de Del sol naciente se desliza primero hacia lo fantástico y luego, por la progresiva aceptación del contraste instalado en lo cotidiano, hacia lo maravilloso. Por otra parte, si sumamos este aspecto a la lejanía del cronotopo, la historia se asimila a un cuento o leyenda japonesa. Este desvío del realismo - paradójicamente - potencia la conexión con la realidad argentina desde una mirada anamórfica que multiplica el sentido de la obra.

En nuestra clasificación del corpus de representaciones de la Guerra

${ }^{7}$ Entre paréntesis respetamos los datos provistos por Lusnich, que indican fecha de escritura de las dos piezas. 
de Malvinas en el teatro argentino (R. Dubatti, 2019: 7-38) reconocemos cinco grupos: 1) textos dramáticos que refieren de manera explícita y central, y/o a través de metatextos, a la Guerra de Malvinas (grupo I); 2) textos que hacen mención a la Guerra de Malvinas en forma lateral (grupo II); 3) textos que refieren de manera general a la guerra, o en particular a otras guerras, pero que potencialmente pueden ser resignificados desde la Guerra de Malvinas (grupo III); 4) textos anteriores a la guerra que son reapropiados desde la dirección / adaptación / recepción desde la problemática de la Guerra de Malvinas (grupo IV); y 5) textos extranjeros sobre la guerra de Malvinas representados o publicados en la Argentina (grupo V).

En dicho trabajo consideramos a Del sol naciente como una poética del grupo I porque, si bien Gambaro trabaja el carácter metafórico del Japón medieval sin referencias explícitas a la Guerra de Malvinas, enuncia el vínculo de su obra con los acontecimientos históricos a través de metatextos periodísticos. Por otra parte, Gambaro incluye en el cronotopo japonés la presencia determinante de topics vinculados a la representación de la Guerra de Malvinas. La ya reconocida concepción artística de Gambaro, siempre comprometida con su contexto político y social, así como la proximidad temporal de los hechos históricos traumáticos, favorecen el vínculo referencial, tanto en la inmanencia de la escritura como en la recepción.

\section{LA GUERRA EN LA ESTRUCTURA DRAMÁTICA}

La guerra constituye un eje clave para la historia y la transformación del personaje de Suki. Del sol naciente es un texto dramático pre-escénico ${ }^{8}$ divido en siete escenas. Toda la acción de la pieza acontece en "una típica casa japonesa" (Gambaro, 2011: 137)9, donde habitan Suki (una cortesana) y Ama (su criada). Examinemos la presencia de la guerra en la estructura dramática de la pieza. De acuerdo con José Luis Alonso de Santos (2007), la estructura dramática es un modelo organizado de relaciones escénicas entre diferentes elementos que nos permite contar una ficción representada

\footnotetext{
${ }^{8}$ Para la clasificación de los textos dramáticos por su relación con la escena, J. Dubatti, 2013: 31-66. ${ }^{9}$ Todas las referencias son extraídas del texto incluido en Gambaro Teatro III. Desde 1980 a 1991 de Ediciones de la Flor (2011: 137-187). En las citas del texto, la bastardilla corresponde siempre a las didascalias, excepto cuando se aclare.
} 
por actores. La estructura teatral no es la mera división de una trama en escenas, cuadros o actos (estructura superficial), sino la relación funcional y causal (estructura profunda) entre las partes que constituyen la obra, en especial entre la trama y los personajes, y sus formas de manifestarse (el lenguaje visual y sonoro) (45-46).

A partir de Alonso de Santos, dividimos el análisis de cada escena en dos instancias: A y B. La primera presenta la estructura profunda. La segunda describe brevemente las acciones, con particular interés en las referencias hacia la guerra.

\subsection{Escena I (137-144)}

A. se introduce un primer grupo de personajes que comienzan a delinear dos perfiles principales. Por un lado, el general Obán se posiciona como representante de una serie de valores guerreros dados como antiguos. Por otro, y en contraste a la actitud sumisa de Ama, Suki se manifiesta como una figura rebelde, crítica de tales tradiciones. La escena opera como planteamiento de la situación dramática a través de dos elementos en principio inconexos: la presencia de un grupo extraño en el pueblo (identificado en escenas subsecuentes) y el anuncio de una guerra.

B. Ama describe a un grupo de personas que ha visto en la calle: “ $¡ O$ Oh, señora, pasaban y todo el mundo con la cabeza hacia el suelo! ¡Las espaldas para abajo y las frentes sobre el polvo! ¡Pasaron ante una corte de ciegos! ¡Nadie se atrevía a mirarlos!” (139). Inmediatamente anuncia la llegada de Obán, que ingresa "vestido con traje medieval de guerrero japonés" (141). El guerrero critica que en la casa “¡Falta algo! Solemnidad, reverencia. (Suki se inclina delante de él.) No. 'Yo' debo inclinarme. (Lo hace.) Ganaremos la guerra. Te lo prometo" (142). Suki inquiere "¿Quién te pidió esa promesa? ¿Qué guerra? ¿Contra quién?” (143). El general responde: "Señora, ¿qué importa contra quién? Siempre hay alguno que nos ofende, que nos quita lo nuestro. Lo tuyo" (143). Suki cuestiona otra vez al general, que afirma: "Lo resolví hoy: ¡tendremos guerra!” (143).

\subsection{Escena II (144-156)}

A. aparece el Tísico, que mendiga comida. Su presencia marca un primer punto de quiebre en Suki. A partir de la situación que Obán fuerza, 
Suki decide romper los lazos con la concepción de mundo del general. A su vez, descubre la posibilidad de entrega hacia el otro a través del amor (en un sentido más bien físico), reflejada en su voluntad de estimular al Tísico. En esta escena se desarrollan los rasgos opuestos de Suki y Obán, asociados con el amor (como acto de entrega hacia el otro) y la violencia (como gesto egoísta), respectivamente. La guerra (una vez más vinculada a los deseos del general) es anunciada como inminente, lo que produce un efecto de tensión dramática.

B. Ingresa el Tísico y Suki le da comida. Llega Obán para despedirse de la cortesana antes de partir a la batalla y expulsa al mendigo. El general intenta llamar la atención de Suki y anuncia que parte a la guerra. Ella simplemente le desea suerte, lo que genera su enojo: “Suerte? ¿Acaso la guerra es cuestión de suerte? ¡Depende de este brazo!” (149). Ante el desinterés de la cortesana, el general hace reingresar al Tísico y trata de obligarla para que bese al mendigo. Como acto de rebeldía, Suki decide besarlo por voluntad propia. Obán la amenaza con un cuchillo, pero lo deja caer.

\subsection{Escena III (156-161)}

A. La guerra ha comenzado y sus consecuencias ya se hacen manifiestas. Se amplía la información sobre las condiciones de la batalla, pero se omiten referencias específicas acerca de dónde o contra quién (datos que finalmente no se explicitarán en ningún momento de la pieza). Obán establece una primera conexión entre sepultura y olvido. La trama de la pieza se encuentra ya en desarrollo.

B. Ama señala que, desde que la guerra comenzó, no hay ni “clientes" ni "fábricas" (156). Obán regresa del frente y reclama atenciones. Ha sufrido una derrota, aunque afirma fue "solo una batalla" (158). Suki observa "estás tan limpio que parece que no hubieras luchado". El general contesta: “¿Si no luché? Si no me hundí en la nieve y en el barro fue para poder mandar. ¡Para que me vieran claramente en medio de la batalla! ¡Esa recua de inexpertos que tuve!” (158). La cortesana inquiere: “¿Quién los llevó a la guerra?”, a lo que el general responde: “¡Yo los llevé! ¡Para que lucharan contra hombres aguerridos, armados hasta los dientes! [...] ¡Porque el espíritu lo puede todo y el valor es la mejor armadura” (158). Obán intenta victimizarse, pero Suki pregunta por los muertos. Obán 
explica que "quedaron allá, helados, mal sepultos. En la primavera van a heder como carroña. Perdimos la batalla. Pero una batalla no es la guerra" (158). Suki vuelve a hacer hincapié en los caídos y Obán, enojado, trata de cerrar la discusión: “¡Basta con ellos! La tierra es nuestra y seguirá siendo nuestra" (158). La cortesana pregunta qué había allí (159), a lo que el general dice "viento y frío y riquezas" (159). Suki recrimina el sentido de hacer una guerra: "Hombres que nos odiaban. Usurpadores que se sentían usurpados. Hubiera sido bueno ganarlos de otra manera, por esto que somos. Atraerlos con esto que somos" (159). Obán toca su espada y replica burlón: "sino con esto; que es también lo que somos" (159). Se oye un ruido, Obán desenvaina su espada y sale. Suki recuerda que Obán mató al Tísico antes de partir. El general retorna asegurando que asesinó a un ladrón, pero su espada no muestra signos de sangre (161).

\subsection{Escena IV (162-165)}

A. Primera aparición de Oscar. No se hacen referencias a la batalla, aunque se comienza a identificar el grupo que Ama describe en la escena I y se lo vincula con la guerra. Los efectos del combate se acentúan y se empieza a perfilar el carácter simbólico / metafísico del texto dramático, con una primer referencia al retorno del ladrón (ahora identificado como Oscar), y con la presencia del viento como recurrencia. Se acentúa el carácter de encierro que presenta la casa, remarcando la construcción de adentro-afuera, proyectado como seguridad y amenaza, respectivamente.

B. Ama afirma que no pueden salir debido al "viento y esos... Se multiplicaron como conejos" (162). Afirma que "trajeron el viento" (162) y los describe:

venían silenciosos. Y a algunos les faltaba la quijada, y a otros las piernas. Se sentaron en la calle, algunos... acostados. Y uno entró en la taberna y pidió de beber [...] Eran muchos. No debian estar donde estaban. Les echaron los perros. Y los perros los mordieron y se oyó el crujido de los dientes en el vacio... (162).

Obán ingresa enojado, afirmando que "se atreven a juzgarme" (163), pero ante los desaires de Suki, se retira. Hace su primer aparición Oscar (165). 


\subsection{Escena V (166-174)}

A. La guerra es descrita largamente por Oscar, con un fuerte énfasis en las malas condiciones de la batalla y en su efecto traumático en los soldados rasos. La presencia de Oscar como caído es determinante para un segundo punto de inflexión en Suki. Su aparición despierta la curiosidad de la cortesana, que intenta comprender mejor tanto la situación de los que no volvieron como la de los que sí retornaron pero se encuentran desamparados. Se contraponen a su vez dos visiones de la gloria guerrera: por un lado, la lógica de Obán, que es de heroísmo; por el otro, la de Oscar, que es de lamento. Aparece una primera asociación entre palabra y memoria, a través de la idea de quitarse el frío hablando. Simultáneamente, Obán refuerza la conexión antes realizada entre sepultura y olvido.

B. Suki interroga a Oscar sobre la batalla. Comenta también que deja comida a la noche pero que desaparece rápidamente. Oscar le explica “¡Son-mu-chos! Una escudilla-¡no basta! ¡El hambre quema y de-ja frío!” (166; respetamos la notación del texto, especialmente el uso singular de guiones). Ama está enojada porque el visitante “itrajo un olor que apesta!" (166). Suki sugiere a Oscar que vuelva "con los otros, se fueron juntos, deben seguir juntos" (166). Este replica que "algunos... ¡vol-vieron!”, a lo que Suki contesta "está bien. Pero vos no" (167). Oscar dice que está helado, que tuvo miedo, frío y hambre (167). Suki trata de convencerlo como si fuera un "chico" (167) y le propone que se junte con los otros, que si van juntos "nadie los atacará. Al contrario. Les regalarán... flores y cintas... Y hasta... Mi señor los honrará”. Oscar se enoja: “QQué es la... ¡honra! de-tu-señor? ¿Cuál-es-la-¡la honra! que-me eligieron?” (167). Ella nota el estado de sus pies y lo frío que está y comienza a frotarle con las manos. Le propone hablar para sacarse el frío. Oscar narra:

Habia estruendo y ese estruendo despedazaba. Nos protegíamos en hoyos, pero el guerrero marcho delante, ;todos los guerreros delante! Sonreía... [...] Sonreía, él y los demás guerreros, sonreían. Montaron en sus caballos, con las espadas desenvainadas, diciéndonos, joh, sin desprecio!, no es con jovencitos que vamos ir a pelear, nosotros, los guerreros. Iban con esa sonrisa desafiante para ganar nuestra tierra, y las bolas de fuego y el estruendo ;los despedazaron, señora!, 
y la nieve los dejó ciegos, y mostraron muñones donde estaban esas piernas tan fuertes que apenas si habian disfrutado, ila vida es tan larga!, ¡Piernas de mujer! (169).

Terminado su relato, recrimina a Suki que hablar no le quitó el frío. Ella pregunta si está contento de haber defendido lo suyo. Este retruca “¿con-ten-to? ¡Está! ¡Está! ¡En la-fo-sa! ¿Qué-mentira-nos llevaron a-defender-si la que ya-teníamos-la-vendieron-en-cada-¡ham-briento!?” (170). Suki y Ama ocultan al soldado detrás de un biombo. Obán regresa y exige un baño. Obán cuenta a Suki que realizaron redadas con el fin de reunir a todos los que combatieron para "dejarlos ahí, en ese corral. Bajo la sed del día y el cierzo de la noche. [...] [Se] consumirán. Y después cercaremos un cementerio -bonito- y la tierra les caerá encima, con honor y olvido. Amén" (172). A su vez, le hace saber a Suki que está al tanto de que Oscar se encuentra en la casa y reclama que "el que fue a la guerra y no sabe quedarse tranquilo como hombre" se vaya (173). Suki cuestiona las palabras de Obán y este ahoga a Oscar en la tina que preparó Ama. El viento aúlla. Sin embargo, Oscar continúa vivo. El general vuelve a hundir su cabeza y dice a Suki: "siempre he tenido que ver con los vivos y con los muertos. Y he sabido manejarme. Porque sé qué fácil es pasar de un estado al otro" (174). Obán sugiere que los muertos vuelven porque no están bien sepultados y exige a Ama que entierre a Oscar "aunque gima" (174).

\subsection{Escena VI (175-182)}

A. Segunda aparición (reaparición) de Oscar. El carácter metafísico de los personajes del Tísico y de Oscar se acentúa. La guerra aparece reflejada como clave de lectura a partir de la discusión sobre los términos héroe / mártir / víctima, atravesados por la gloria y la muerte. Estas ideas contraponen a Suki y Obán como dos perspectivas de mundo irreconciliables. Se explicita la relación de complicidad entre el poder guerrero (Obán) y la población civil (Ama), que pasa de ser de fascinación a acción, enterrando a Oscar por primera vez. El olor deviene ya no como síntoma de putrefacción, sino como marca de la responsabilidad de los participantes de la guerra.

B. Ama cuenta que le duele la espalda tras enterrar al soldado y que Obán "caminó encima de la tierra apisonada" (175). Suki le discute 
que estuviera muerto. Obán ingresa y solicita un baño. Ya fuera de la tina, Suki comenta al guerrero que huele "a muerto" (178). Oscar reaparece en la casa. Suki le pide a Ama que le traiga un quimono para ocultarlo. Oscar le advierte que hiede, pero ella responde "todo el mundo hiede [...] con otros olores. Más astutos, más insoportables. Tu olor es limpio" (180). Lo disfrazan y vuelve a ingresar Obán, que sospecha del joven, que Suki afirma es su hermano menor, y finalmente lo descubre: “¡Yo sé quién es! ¡Un héroe! [...] acá hay héroes o tarados. Si no sos un héroe, ¿qué sos? [...] ¡un martir!" (182-183). Suki contesta indignada que "quien no elige su martirio, no es mártir, ¡es víctima!” (182). Obán increpa a Oscar y le recrimina que no acepta la gloria porque no acepta la muerte. Como puede, Oscar contesta que sí quiere y Obán afirma que cuando él mismo muera va a estar contento de haber defendido lo suyo. Obán se enfurece y atraviesa con su espada a Oscar.

\subsection{Escena VII (182-187)}

A. Segundo entierro de Oscar. Tercera aparición del caído. Suki completa su toma de conciencia y decide partir con Oscar para reunirse con los otros que estuvieron en la guerra. La austeridad que la cortesana antes sugería en sus críticas, se proyecta ahora en el cuerpo como acto de igualación con el otro $^{10}$. La transformación de Suki se refleja en el reconocimiento de Oscar, que la llama "madre" (187). Se explicita la noción de la memoria como apertura y entrega al otro, al tiempo que se la desvincula de la idea de tradición (clave para entender la lógica patriarcal que Gambaro trata de dislocar).

B. Ama cuenta que enterró por segunda vez a Oscar. Comienza a pensar un nuevo plan para llamar la atención de Obán, pero la cortesana se quita la peluca y continúa desvistiéndose hasta quedar en su "túnica interior" (184). Se oye un roce en la puerta exterior. Ama intenta que Suki no salga, pero esta llama a Oscar. Ama le dice "no hay nadie. Algún perro arañando la puerta. Rumores. Del viento. $\mathrm{Y}$ esos, esos que hedían, ni yo creo que hayan existido. Nunca los vi" (184). Suki insiste en llamar a

\footnotetext{
${ }^{10}$ Lusnich (2001b) sugiere que el gesto de quitarse la peluca representa un guiño teatralista, de autorreferencia teatral. Es posible realizar tal lectura, aunque consideramos que posee un mayor peso el uso simbólico del acto de ponerse en el lugar del otro. No se trata de un acto de "anulación del propio cuerpo" (Heredia, 2013: 47), sino de adecuarse a las condiciones del otro.
} 
Oscar, que aparece por detrás del biombo. La cortesana decide ir junto al soldado. Suki pregunta a Oscar: “¿me llevarás con los otros? [...] Prepararé comida. Los sentaré en mi mesa. Comeré con ellos. Hablaré con ellos. Sabré lo que padecieron [...] y entonces podrán morir en paz. La memoria es esto: un gran compartir" (185). Ama afirma "soy vieja, acostumbrada al respeto", a lo que Suki opone "ni irrespetuosidad ni respeto. La vida es otra cosa. Corre por otro lado" (186). Ante la mirada perpleja de la criada, el soldado dice que quiere estar "¡mu-muerto! ¡En... paz!” (186). Suki

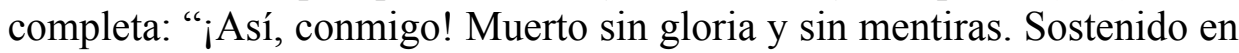
la calle, caminando conmigo, poniéndome palabras en la boca. Revelado. No te negaré. Ni la tierra ni el fuego los negarán. Ni el futuro los negará" (186). La pieza concluye con Oscar llamando “¡Maaaaa-dre! ¡Maaaa-dre!” (187) a Suki.

Sin guerra no hay memoria ni sentido crítico posibles en Del sol naciente. No se trata de un simple trasfondo para la relación entre Suki y Obán, como se ha sugerido (Tarantuviez, 2007; Heredia, 2013, entre otros). Por el contrario, es el elemento que posibilita un cambio en el carácter de la cortesana y radicaliza sus diferencias críticas - cuyo germen portaba previamente - con el general y su patriarcal tradición de espada. Sin el conflicto bélico, sus efectos económicos — la falta de "fábricas" y "clientes" (156) — y sociales — el Tísico, Oscar, los "esos" que están fuera de la casa (176) - Suki no podría realizar un movimiento que la lleve de la rebeldía a la acción concreta, de la indiferencia al acto de apertura desinteresada hacia el otro. No se trata entonces de una mujer plenamente idealizada (Tarantuviez, 2007: 146), aunque, como veremos, sí representa un potencial de cambio social (Witte, 1996).

\section{DEL SOL NACIENTE: CAMPO REFERENCIAL EXTERNO E INTERNO}

Benjamin Harshaw (1984: 227-251) distingue entre campo referencial externo (CRE) y campo referencial interno (CRI). El primero opera en el texto de manera centrífuga, apuntando hacia el exterior del universo poético de la pieza. Consiste en las referencias que se construyen sobre el mundo que rodea a la obra, fuera de ella. En contraste, el campo referencial interno actúa en un sentido centrípeto, reenvía hacia el centro de la poiesis, tanto en lo intrarreferencial de la ficción (la cohesión de su 
historia, sus personajes, espacio, tiempo, etc.) como en la autorreferencia sígnica (lo metalingüístico implícito o explícito). En Del sol naciente Gambaro construye un universo poético ambiguo, plurívoco (Eco, 1984) donde la guerra, simultáneamente, es y no es la Guerra de Malvinas Para lograr este efecto de tensión no resuelta, al mismo tiempo que no hace referencias explícitas, incorpora en las situaciones topics en los que ancla la representación de la guerra de 1982.

Si en términos de Eco (1993), los topics consisten en imágenes que estimulan inferencias abductivas en el lector / espectador, mediante su uso es posible acotar el sentido al que apunta estratégicamente un texto (125134). En otras palabras, se trata de referencias que se interconectan entre sí y resuenan juntas en el espectador debido a que se encuentran inscriptas en los imaginarios (Baczko, 1999) de una sociedad particular en un momento histórico dado. Su capacidad de acotar sentido radica en su habilidad para direccionarlo hacia ámbitos potencialmente familiares para el receptor, lo que implica un lector ideal con unas competencias culturales particulares. Mientras más fuerte sea la presencia de esos imaginarios - que operan como un entramado que enlaza diferentes topics-, más factible es que el sentido de una pieza se pueda acotar de una manera más específica

Podemos señalar al menos cinco topics que direccionan la guerra de la pieza hacia los acontecimientos de la Guerra de Malvinas: 1) el soldado indigente; 2) el militar de escritorio; 3) el clima extremo; 4) el muerto que retorna (en su variante involuntaria); y 5) la madre protectora ${ }^{11}$. Acompañamos cada descripción con citas del texto dramático.

\subsection{El soldado indigente}

Consiste en la representación de los combatientes como figuras en la intemperie en situación de desamparo institucional, arrojados sin medios a la guerra. Esto aplica tanto a las condiciones extremas de frío en las islas y la falta de recambio de indumentaria, la pobre alimentación, como a la Posguerra en la que muchos excombatientes mendigaban en espacios públicos, especialmente aquellos que habían quedado física y / o psicológicamente afectados (Lorenz, 2012). Esto se sugiere en las

${ }^{11}$ Redactamos actualmente el capítulo de nuestra tesis que incluye un inventario completo de topics de la Guerra de Malvinas. 
reiteradas descripciones que realiza Ama al comienzo de las escenas I (139), II (144) y IV (162). El Tísico también puede asociarse a la descripción de un excombatiente, de acuerdo con los testimonios que ya circulaban en el momento (Kon, 1982): se presenta avergonzado de pedir comida y Suki comenta que su ropa le parece "liviana" para el frío (147). La referencia a "un ladrón calentándose al fuego" (161) reenvía a los valores trastocados de la guerra, donde robar comida para sobrevivir representaba un crimen pasible de fuerte sanción por parte de los superiores (Lorenz, 2012). La presencia de Oscar y su descripción (165) entrelazan este topic con el muerto que retorna.

\subsection{El militar de escritorio}

Se articula a partir de la actitud de algunos cuadros (militares superiores en jerarquía) de mantenerse en la retaguardia para dirigir la batalla (Lorenz, 2009), privilegiando un rol administrativo al (potencial) honor de estar en el campo de batalla ${ }^{12}$. Se presenta a través del personaje de Obán, que representa los valores del nacionalismo militar (Guber, 2001) y promete ganar "la guerra", aunque el enemigo no es claro y el combate parece una decisión unilateral (143). Critica la idea de que la guerra dependa de la suerte y su actitud hacia Suki y el Tísico se asocia al sadismo de los torturadores durante la guerra antisubversiva, actos también ocurridos en las islas. No obstante, su condición burocrática se explicita durante la escena III. Suki recrimina a Obán estar demasiado limpio para haber peleado, el general retruca que si no se hundió en la "nieve ni en el barro" fue para que lo vieran mandar (158). Esto redimensiona su personaje debido a que pone en evidencia la no coincidencia entre valores, actos y palabras, elemento fundamental para la construcción de sentido de la pieza.

\footnotetext{
${ }^{12}$ En esta actitud "de escritorio" se proyectaba también la crítica a aquellos cuadros que estaban más vinculados en su carrera militar con cuestiones burocráticas que con un trabajo "de campo". Empleamos este término debido a que la guerra radicaliza esta crítica que circulaba entre las fuerzas antes de Malvinas y que va a ser significativa al momento del levantamiento carapintada de semana santa de 1987 (Robledo, 2017).
} 


\subsection{El clima extremo}

Las Islas Malvinas, debido a su ubicación geográfica poseen unas características climáticas particulares — frío, turba húmeda, poca vegetación, ausencia de árboles, vientos fuertes-, que en muchas ocasiones se sugieren como hostiles. También se asocia con los recursos naturales de la región: las "riquezas" (159) de las islas. Este es un topic clave, debido a que constituye uno de los más recurrentes en las representaciones teatrales y no teatrales de Malvinas. A la referencia antes señalada a la nieve y el barro (158), se suma la de los soldados "helados, mal sepultos" (158), situación de muchos caídos, que no pudieron ser debidamente enterrados debido al retroceso de las tropas en el campo de batalla ${ }^{13}$. Resuena una vez más el paisaje malvinense cuando Obán dice: “¿Qué hay? Viento y frío y riquezas" (159). Las condiciones extremas del paisaje se proyectan metonímicamente a las de la difícil subsistencia a través de la asociación entre hambre, quemadura y frío (166) o la referencia al fuerte olor de los combatientes (166) por los hábitos de higiene alterados.

\subsection{EI muerto que retorna (variante involuntaria)}

Este es uno de los topics más significativos de la Guerra de Malvinas, vinculado al carácter traumático de los acontecimientos. En el caso de Del sol naciente, se trata de su variante involuntaria ${ }^{14}$. Oscar opera como la figura que permite acercar al espectador el espacio del campo de batalla, con la garantía adicional de ser un testigo del horror en su expresión más directa (Primo Levi, 2015). Esto permite no sólo retomar las condiciones extremas de la guerra, sino que posibilita el recurso de la prosopopeya, darle voz a los que ya no están. Así, Oscar señala que no hay honra en haber sido elegido para la guerra (167), remarca la jerarquización entre cuadros y conscriptos, vuelve a referirse a "nuestra tierra", habla

\footnotetext{
${ }^{13}$ La labor de entierro de los caídos argentinos fue realizada por militares ingleses, estuvo a cargo del coronel Geoffrey Cardozo, integrante del área de logística del Ministerio de Defensa en Londres.

${ }^{14}$ Distinguimos al menos tres tipos diferentes de este tópico: a) el muerto que regresa voluntariamente (como lo hace el protagonista de Malvinas, canto al sentimiento de un pueblo, 1992, de Oscar Buzzo y Néstor Zapata); b) el muerto que regresa a través de la memoria / el recuerdo de otro (Retaguardia, 1985, de Horacio Del Prado); c) el muerto que regresa involuntariamente. En este último caso, los muertos retornan incluso en contra de su voluntad, forzados por un motivo que no llega a explicitarse, pero que los lleva a seguir (re)apareciendo.
} 
de "bolas de fuego" - donde resuenan los bombardeos nocturnos de los ingleses-, menciona nuevamente el clima y la falta de preparación $\mathrm{y}$, finalmente, habla de los soldados mutilados (169). Sus comentarios se asocian a su vez con las políticas económicas del gobierno de facto (170): “QQué-mentira-nos llevaron a-defender-si la que ya-teníamos-lavendieron-en-cada-¡ham-briento!?" (170) ${ }^{15}$. Suki le pregunta a Ama si no habrá otros caídos en otras casas que no se quieran ir (170), lo que sugiere que la situación de Oscar puede replicarse en otros espacios. En contraste a esta presencia involuntaria del combatiente caído, Obán hace referencia a la idea de construir un cementerio y enterrar a los soldados "con honor y olvido" (172). Más adelante, el general descubre a Oscar y lo tortura mientras "se alza el viento" (173), situación que remite a los crímenes de lesa humanidad ocurridos en las islas ${ }^{16}$. Esto se complementa con el comentario de Ama, que enterró a Oscar para que luego Obán camine encima (175). Aquí se entraman no sólo los enterramientos vivos, práctica de tortura habitual como castigo durante la guerra (Niebieskikwiat, 2012: 59-64), sino también la idea de la memoria como acto de des-ocultamiento.

\subsection{La madre protectora}

En esta figura resuenan por un lado las madres biológicas y putativas de los soldados, las madrinas de guerra (Lorenz, 2009), así como las Madres de Plaza de Mayo y la Matria (versión femenina de la representación de la Nación Argentina que cobija y ampara). Esto va a permitir que se vincule lo femenino con una perspectiva contraria a la violencia, como desarrollaremos al hablar de la producción de sentido de la pieza. A lo largo de las representaciones de Malvinas en el teatro, se hace presente de manera recurrente la madre como figura contenedora. En este caso, la pieza no incluye su contraparte: el padre como figura de imposición social. Suki

\footnotetext{
${ }^{15}$ En estas palabras bien podrían hacerse eco las observaciones de León Rozitchner durante su polémica con el Grupo de Discusión Socialista. En ellas cuestiona la actitud presuntamente "anticolonialista" de la guerra al afirmar que todavía se mantenía una fuerte relación de dependencia económica con los mismos oponentes a los que se quería derrotar (2015).

${ }^{16} \mathrm{Al}$ momento de redacción de este trabajo, continúan las investigaciones por los crímenes de lesa humanidad ocurridos durante la guerra. Véase por ejemplo el artículo "Torturas en Malvinas: llaman a indagatoria a 18 militares imputados", escrito por Pablo Roesler, publicado el 6 de diciembre de 2018 en el diario Tiempo Argentino: https://www.tiempoar.com.ar/nota/torturas-en-malvinasllaman-a-indagatoria-a-18-militares-imputados [20/04/2019].
} 
marca la conexión entre maternidad y comida (168). A su vez ofrece un oído que escuche las experiencias de Oscar, porque "a veces las palabras nos quitan el frío" (168), lo que puede leerse en relación al silencio y la autocensura a la que se llaman muchos excombatientes (Lorenz, 2012). Más adelante, Suki intenta ocultar a Oscar como si fuera su hermano menor, "demasiado joven" para pelear (181). Finalmente, hacia el final de la pieza, Suki asume explícitamente un rol maternal, siendo Oscar quien la reconoce como tal: “¡Maaaaa-dre! ¡Maaaa-dre!” (187).

En vista del uso de estos topics, que se contraponen a la voluntad de no hacer explícita la relación entre la guerra de la pieza y la Guerra de Malvinas, consideramos a Del sol naciente como una poética de la anamorfosis. Se trata de un recurso pictórico que consiste en la deformación reversible de una imagen generada a través de un procedimiento óptico o matemático ${ }^{17}$. Así, en la pieza de Gambaro, los topics delinean un dibujo deformado que puede ser recuperado desde una perspectiva específica no directamente explicitada: la Guerra de Malvinas. Esta poética no se arraiga en una transparencia de sentido sino más bien en el principio dinámico que se genera desde las fricciones entre texto, contexto y cotexto (Eco, 1993), pasible de ser revertido a través de las inferencias que ofrecen los topics. Esto es especialmente relevante cuando se contempla la cercanía del texto con los hechos históricos. Este entramado de referencias opera como un modo de decir aquello sobre lo que se callaba al momento del estreno de la pieza (en 1984 todavía no había ocurrido el juicio a la Junta Militar, pero ya es posible hablar de un primer proceso de desmalvinización) $)^{18}$.

\footnotetext{
${ }^{17}$ Cabe señalar que al referirnos a este recurso pictórico, no estamos pensando en su empleo en una obra como Jean de Dinteville y Georges de Selve (habitualmente conocida como "Los embajadores") de Holbein el Joven. Más bien pensamos en piezas como Érection de la Croix de Domenico Piola, que consisten en un cuadro deformado pasible de ser revertido empleando un espejo cilíndrico que se coloca en el punto central de la obra. Hemos hallado el mismo procedimiento anamórfico en la pieza de Javier Daulte Casino. Esto es una guerra (R. Dubatti, 2018).

${ }^{18} \mathrm{La}$ "desmalvinización" representa los procesos de omisión que la guerra y la causa Malvinas sufren desde el final del conflicto bélico. Habitualmente asociada con la idea de silencio, se puede apreciar en contextos muy diferentes - diplomacia, soberanía, reconocimiento a los excombatientes, historia, etc.- lo que complejiza su interpretación (Cangiano, 2012).
} 


\section{LA GUERRA DE MALVINAS DESDE UNA ÓPTICA FEMINISTA}

De este modo, la guerra de Del sol naciente conecta las coordenadas de dictadura / nacionalismo / militarismo / Guerra de Malvinas. A través de un campo referencial ambiguo, del desplazamiento de coordenadas cronotópicas ficcionales y del uso de topics a la manera de una anamorfosis, Gambaro conceptualiza la Guerra de Malvinas como parte del proceso de violencia del gobierno dictatorial, arraigado sobre una concepción de mundo específica: el patriarcado ${ }^{19}$.

La ambientación en el Japón feudal opera como una puesta en distancia. La metáfora puede operar tanto por semejanza (Oliveras, 2007) como por desemejanza (Rozik, 2008), por lo que puede, simultáneamente, generar puntos de contacto y de divergencia. Así, Del sol naciente no sólo abre un universo exótico tanto para la autora como para el espectador, sino que a su vez permite focalizar en el carácter estructural de la violencia patriarcal. La distancia espacio-temporal (entre el Japón medieval y la Argentina de postdictadura en 1984) se vuelve accesoria porque los problemas (y las soluciones) son los mismos indistintamente de las coordenadas: sucede lo mismo en todas partes

Esto se enfatiza a través de los vínculos que entablan Suki y Obán, construidos desde una serie de dicotomías: lo maternal / lo paternal; el amor / la violencia; el deber de la memoria / el deber de la tradición, respectivamente. Ambos representan una concepción de mundo particular. Suki rechaza las relaciones de poder y finalmente decide abocarse al cuidado de Oscar y de los que vuelven. Obán, en contraste, responde a una tradición de espada, marcada por el orgullo y los honores del éxito militar. Mientras que Suki es inconformista y cuestiona todo, Obán naturaliza la violencia y la proyecta de manera constante hacia aquellas figuras que encuentra inferiores (el Ama, Oscar, el Tísico) o que quiere subyugar (Suki, quien nunca cede antes sus presiones, ni siquiera bajo amenaza). Como sugieren las respuestas de Ama y el Tísico, la concepción de mundo de Obán representa el statu quo social, las reglas hegemónicas mediante las cuales (hipotéticamente) se deberían manejar todos los personajes. El gesto de rebeldía de Suki, coronado con su entrega al final de la obra,

${ }^{19}$ Para un desarrollo in extenso de estas nociones, remitimos al valioso trabajo de Contreras (1994b). 
marca un acto de quiebre con la lógica militar, masculina y patriarcal (Witt, 1996). Suki lleva ese germen de rebeldía en ella (Ragué, 1994: 65), pero no se trata de un personaje idealizado (en los términos de Tarantuviez, 2007), sino que realiza un desplazamiento que le permite transformar sus ideas en acciones.

Suki y Obán son opuestos también desde la perspectiva de la memoria. A través de sus encuentros con el Tísico y con Oscar, Suki pasa a comprender el valor de la apertura hacia el otro y afirma que "la memoria es esto: un gran compartir" (186). La memoria es concebida como un patrimonio colectivo y mutable (Halbwachs, 2004) que incluye un sentido moral: está unida a la justicia y la verdad. Suki dice a Oscar: “ ¡Apretado, confortado! ¡Así, conmigo! Muerto sin gloria y sin mentiras. Sostenido en la calle, caminando conmigo, poniéndome palabras en la boca. Revelado" (186; énfasis nuestro). La memoria es acompañar y ser acompañado. Trastoca así la mezquina idea de orden que se desprende de la tradición guerrera de Obán. En términos de Todorov (2000), Suki representa una memoria ejemplar, universal, guiada por un concepto de bien y de utilidad. En contraste, Obán es vinculable con la idea de una memoria literal, interesada y manipulable, que responde a su beneficio personal.

En este marco, Oscar aparece como muerto que regresa, como ausencia presente. Sus recurrentes muertes a manos de Obán no lo detienen porque la memoria recorre un camino diferente al de la violencia. Simultáneamente, Gambaro emplea su figura para introducir un procedimiento de prosopopeya. Si, en consonancia con las ideas de Primo Levi (2015), la verdadera experiencia de la guerra es la de los muertos (Suki pregunta en diversas ocasiones por ellos), darles voz implica cubrir "lagunas" (Agamben, 2000: 22) que sólo los protagonistas podrían cubrir. Así, el viento no sólo es referencia al clima del campo de batalla, sino que también es el vacío y la injusticia. El orden natural de la verdad y la justicia que Gambaro entiende que acompaña la memoria, se ve trastocado, y el viento permite evidenciar ese silencio / ausencia.

Los excombatientes aparecen encerrados entre la lógica de la guerra y la lógica del patriarcado (íntimamente vinculadas). En esta zona intermedia, es más fácil borrar a los soldados de la memoria (como intenta Obán, pidiendo a Ama que se encargue de enterrar a Oscar al menos dos veces), que reconocerlos y reexaminar los valores sobre los cuales se 
construye la sociedad. Sin embargo, no se trata simplemente de personajes que "son puro instinto sufriente que requiere 'dirección" como sugiere Heredia (2013: 51; énfasis en el original). Por el contrario, poseen al menos dos características que les otorgan un valor diferente y significativo en la pieza: en primer lugar, tienen una capacidad de resistencia (involuntaria), incluso a su pesar vuelven para reclamar memoria y justicia; en segundo, como vimos antes, tanto el Tísico como Oscar posibilitan que Suki comprenda desde la acción las ideas que ya portaba. De este modo, Gambaro, a través de la cortesana y de su encuentro con los efectos de la batalla y la violencia (no sólo física sino también económica y social), propone reexaminar el marco social, histórico y político, que hicieron y hacen posibles dictaduras y guerras.

Del sol naciente sugiere así una multiplicidad de sentidos desde el nombre de la pieza. Remite a su vínculo con el Japón feudal, sin embargo, es posible enlazar tal referencia con la noción de reinicio, el final de la noche y el comienzo de un nuevo día. Finalmente, y a través de este juego metafórico, se conecta con el cambio de mentalidad de Suki, quien explicita una serie de transformaciones - ya no atender a abusivos como Obán (152) / la renuncia a los regalos (144) y el dinero (156) / la entrega plena y desinteresada al otro (186-87) — que concluyen en una epifanía: el tiempo nuevo de la memoria como "un gran compartir" (185), que trasciende los intereses del poder y la perspectiva patriarcal para abrir una nueva época. Al hablar la pieza del (sobre el) sol naciente, el texto dramático intenta echar luz sobre las sombras de la dictadura y la Guerra de Malvinas.

\section{REFERENCIAS BIBLIOGRÁFICAS}

AGAMBEN, G. (2000). Lo que queda de Auschwitz. Homo Sacer III. Valencia: Pre-Textos.

ALONSO DE SANTOS, J. L. (2007). Manual de teoría y práctica teatral. Madrid: Castalia Universidad.

BACZKO, B. (1999). Los imaginarios sociales. Memorias y esperanzas colectivas. Buenos Aires: Nueva Visión.

BARRENECHEA, A. M. (1978). "Ensayo de una tipología de la literatura fantástica (a propósito de la literatura hispanoamericana". En Textos 
hispanoamericanos. De Sarmiento a Sarduy, 87-103. Caracas: Monte Ávila.

BOTTA, M. (2006). "Bar Ada, de Jorge Leyes y la guerra de las Malvinas en la ficción teatral". CiberLetras 14. Disponible en línea: http:// www.lehman.cuny.edu/ciberletras/v14/botta.htm [24/04/2019].

CANGIANO, F. (2012). “Desmalvinización'. La derrota argentina por otros medios". Revista de la Facultad de Ciencias Sociales 80 (abril), 28-37.

CATENA, A. (1984). "Entrevista. Última pieza de Griselda Gambaro: una nítida metáfora del sol naciente". El Periodista 4, 34-35.

CATTARUZZA, A (2012). "Dimensiones políticas y cuestiones historiográficas en las investigaciones históricas sobre la memoria". Storiografía 16, 71-91.

CHARTIER, R. (1992). El mundo como representación. Estudios sobre historia cultural. Barcelona: Gedisa.

CICCONE, C.; HEREDIA, J.; IRAZÁBAL, P. y SUÑER, N. (2017). Malvinas en el aula. Una propuesta desde la literatura. Viedma: Universidad Nacional del Comahue.

CONTRERAS, M. (1994a). "Diagnosis de la pareja: el samurai y la geisha. Del sol naciente de Griselda Gambaro". En Del rito a la posmodernidad, S. Pereira Poza (ed.), 69-81. Santiago: IITCTL.

(1994b). Griselda Gambaro. Teatro de la descomposición. Concepción: Universidad de Concepción.

DUBATTI, J. (2012a). Cien años de Teatro Argentino. Desde 1910 a nuestros días. Buenos Aires: Biblos.

(2012b). Introducción a los estudios teatrales. Propedéutica. Buenos Aires: Atuel.

(2013). "Filosofía del Teatro, acontecimiento teatral: cambios en los conceptos de drama, dramaturgia, texto dramático, poética dramática y notación dramática”. En $V$ Congreso Internacional de Dramaturgia Hispanoamericana Actual, C. Figueroa Acevedo y A. Quintana Fuentealba (comps.). 31-66. Valparaíso: Universidad de Valparaíso / Facultad de Arquitectura / Carrera de Teatro.

DUBATTI, R. (2018). "Casino. Esto es una guerra (1997), de Javier Daulte: 'onírica revisión' de la Guerra de Malvinas". CELEHIS. Revista del Centro de Letras Hispanoamericanas 34 (julio), 194209. 
(2019). "Prólogo. Teatro de la guerra: corpus de representaciones de la Guerra de Malvinas en textos dramáticos y espectáculos". En Malvinas 2. La guerra en el teatro, el teatro de la guerra, R. Dubatti (comp.), 7-38. Buenos Aires: Ediciones del CCC.

ECO, U. (1984). Obra abierta. Barcelona: Planeta-Agostini.

(1993). Lector in fabula. La cooperación interpretativa en el texto narrativo. Barcelona: Lumen.

ESCUDERO, L. (1997). Malvinas: el gran relato. Fuentes y rumores en la información de guerra. Barcelona: Gedisa.

FERRARI, G. (2013). 1983. El año de la democracia. Buenos Aires: Planeta.

GAMBARO, G. (2011). "Del sol naciente". En Gambaro Teatro III. Desde 1980 a 1991, 137-187. Buenos Aires: Ediciones de la Flor.

GRAHAM-JONES, J. (2000). Exorcising History. Del sol naciente. Griselda Gambaro.

GUBER, R. (2001). ¿Por qué Malvinas? De la causa nacional a la guerra absurda. Buenos Aires: FCE.

HALBWACHS, M. (2004). Los marcos sociales de la memoria. Caracas: Anthropos.

HARSHAW, B. (1984). "Fictionality and Fields of Reference. Remarks on a Theoretical Framework". Poetics Today 5.2, 227-251.

HEREDIA, M. F. (2013). "Del ayuno o la integridad de la razón en el teatro de Gambaro. Acerca de Del sol naciente". En Pensar la escena. Homenaje a Osvaldo Pellettieri. M. Rodríguez y M. Sikora (eds.), 43-54. Buenos Aires: Corregidor.

JELIN, E. (2002). Los trabajos de la memoria. Madrid: Siglo XXI.

KON, D. (1982). Los chicos de la guerra. Hablan los soldados que estuvieron en Malvinas. Buenos Aires: Galerna.

LEVI, P. (2015). Asi fue Auschwitz: testimonios 1945-1986. Barcelona: Península.

LORENZ, F. (2009). Malvinas. Una guerra argentina. Buenos Aires: Sudamericana.

(2012). Las guerras por Malvinas. Buenos Aires: Edhasa.

LUSNICH, A. L. (2001a). "El realismo crítico de Griselda Gambaro y Eduardo Pavlovsky (1976-1983)"'. En Historia del teatro argentino en Buenos Aires (volumen V). El teatro actual (1976-1998), O. Pellettieri (dir.), 146-156. Buenos Aires: Galerna. 
(2001b). "Cambio y continuidad en el realismo crítico de Griselda Gambaro y Eduardo Pavlovsky". En Historia del teatro argentino en Buenos Aires (volumen V). El teatro actual (1976-1998), O. Pellettieri (dir.), 341-352. Buenos Aires: Galerna.

MANCUSO, H. R. (2010). De lo decible. Entre semiótica y filosofia: Peirce, Gramsci, Wittgenstein. Buenos Aires: Editorial SB.

(2011). "Constelaciones textuales y responsivas entre anarquismo y nacionalismo del centenario a la posguerra". En Nacionalistas y nacionalismos. Debates y escenarios en América Latina y Europa, F. Mallimaci y H. Cuchetti (comps.), 63-84. Buenos Aires: Gorla.

MARTINI, S. M. (1989). "El ambiguo protagonismo de las palabras en el teatro de Gambaro". En Poder, deseo y marginación. Aproximaciones a la obra de Griselda Gambaro, N. Mazziotti (comp.), 95-107. Buenos Aires: Puntosur.

MINISTERIO DE EDUCACIÓN DE LA NACIÓN (2009). Pensar Malvinas. Una selección de fuentes documentales, testimoniales, ficcionales y fotográficas para trabajar en el aula. Buenos Aires: Ministerio de Educación de la Nación.

NIEBIESKIKWIAT, N. (2012). Lágrimas de hielo. Torturas y violaciones a los derechos humanos en la guerra de Malvinas. Buenos Aires: Norma.

OLIVERAS, E. (2007). La metáfora en el arte. Retórica y filosofía de la imagen. Buenos Aires: Emecé.

PAVLOVSKY, E. (1976). Reflexiones sobre el proceso creador / El señor Galíndez. Buenos Aires: Proteo.

PRESAS, M. A. (1997). La verdad de la ficción. Buenos Aires: Almagesto. RAGUÉ, J. M. (1994). "El teatro de Griselda Gambaro contemplado desde la perspectiva de la crítica feminista". En Del rito a la posmodernidad, S. Pereira Poza (ed.), 59-67. Santiago: IITCTL.

ROBLEDO, J. (2017). Felices Pascuas. Breve historia de los carapintadas. Buenos Aires: Planeta.

ROESLER, P. (2018). "Torturas en Malvinas: llaman a indagatoria a 18 militares imputados". Tiempo Argentino, 6 de diciembre. Disponible en línea: https://www.tiempoar.com.ar/nota/torturas-en-malvinasllaman-a-indagatoria-a-18-militares-imputados [24/04/2019].

ROZIK, E. (2008). Metaphoric thinking. A study of nonverbal metaphor in the arts and it's archaic roots. Tel Aviv: Tel Aviv University. 
(2014). Las raíces del teatro. Repensando el ritual y otras teorías del origen, trad. Ricardo Dubatti y Nora Lía Sormani. Buenos Aires: Editorial Colihue.

ROZITCHNER, L. (2015). Las Malvinas: de la guerra "sucia” a la guerra "limpia”. Buenos Aires: Biblioteca Nacional.

SVANASCINI, O. (1976). Tres maestros del haiku Buenos Aires: Torres Aguero Editor.

SZONDI, P. (1994). Teoría del drama moderno / Tentativa sobre lo trágico. Barcelona: Destino.

TARANTUVIEZ, S. (2007). La escena del poder. El teatro de Griselda Gambaro. Buenos Aires: Corregidor.

TODOROV, T. (2000). Los abusos de la memoria. Barcelona: Paidós.

TORRES, V. (2016). "Más cerca del cañón que del canon: las primeras ficciones de la guerra de Malvinas". En Relatos de Malvinas. Paradojas en la representación e imaginario social nacional, M. Semilla Durán (comp.), 178-191. Villa María: EdUVIM.

VEZZETTI, H. (2002). Pasado y presente. Guerra, dictadura y sociedad en Argentina. Buenos Aires: Siglo XXI.

VITULLO, J. (2012). Islas Imaginadas. La Guerra de Malvinas en la literatura y el cine argentinos. Buenos Aires: Carregidor.

WITTE, A. (1996). Guiding the plot. Politics and Feminism in the Work of Women Playwrights from Spain and Argentina, 1960-1990. Nueva York: Peter Lang.

Recibido el 1 de abril de 2019.

Aceptado el 8 de mayo de 2019. 